\title{
A practical prescreening method for sloshing severity evaluation
}

\author{
Miao-Zi Zheng ${ }^{1} \cdot$ Ying Gou $^{2} \cdot$ Bin Teng $^{2} \cdot{\text { Hyojae } \mathrm{Jo}^{3}}^{3}$
}

Received: 27 October 2019 / Published online: 14 May 2020

(c) The Author(s) 2020

\begin{abstract}
This paper aims at finding a proper way to estimate sloshing severity. First, the concept of sloshing severity RAO (SSR) is introduced, and the wave elevation on the liquid free surface is chosen as an initial index for the rough prediction of sloshing severity. Then, compared with experimental data from a 3D regular model test, this index is adjusted and a new index is generated. One step further, sloshing severity under irregular sea states can be achieved by nonlinear combinations of the new index. For validation, the same model tank is tested under a set of irregular sea conditions, and peak pressures and impulse areas are taken as comparison standards. It is found that both numerical and experimental results show a similar tendency of sloshing severity. As a real ship application on the new index, the sloshing severity of a liquefied natural gas floating production storage and offloading (LNG-FPSO) is predicted under a low filling condition. Besides, the ship motion responses with and without sloshing effects are considered for the calculation of severity. From the present observation, this proposed methodology and generated new index is expected to be applicable to the selection of severe sea states for sloshing loads analysis.
\end{abstract}

Keywords Sloshing severity $\cdot$ Model test $\cdot$ Prescreening $\cdot$ Sloshing assessment

\section{Introduction}

This paper is devoted to the evaluation of the sloshing severity inside LNG tanks, in a fast but reasonably accurate way. The phenomenon of fluid motion in a partially filled tank due to the tank motion is known as sloshing. With the increased activities in the LNG transport around the world, sloshing has been considered as a very important practical problem. In the past, LNG ships were allowed to operate either in full or empty tank conditions, while today there is a necessity to allow for sailing at any partial filling. As a result, violent sloshing motions may occur and the direct consequence is

Edited by Xiu-Qiu Peng

Miao-Zi Zheng

zhengmiaozi@snu.ac.kr

1 Department of Naval Architecture and Ocean Engineering, Seoul National University, Seoul 08826, Korea

2 State Key Laboratory of Coastal and Offshore Engineering, Dalian University of Technology, Dalian 116024, China

3 Department of Naval Architecture and Ocean Systems Engineering, Korea Maritime and Ocean University, Busan 49112, Korea the large impact situation and possible damage of the LNG Cargo Container System (LNG CCS).

So far, sloshing waves in moving tanks have been studied analytically, numerically, and experimentally, and these studies have explored a great range of the sloshing wave, from linear and nonlinear phenomena to the effect of viscosity. Fundamental work on axial-symmetric tanks has been motivated by the space industry (Abramson 1966), and then Abramson et al. (1974) introduced the potentially dangerous loads on ship tanks. Faltinsen et al. (2000), Faltinsen and Timokha (2009), and Faltinsen et al. (2005) came up with a modal system method for analytical approach. Since analytical solutions have limitations such as geometry restriction, model testing has been considered as the most reliable method in predicting the maximum impact pressure due to violent sloshing. Yung et al. (2009) studied sloshing model test and identified relevant dimensionless numbers necessary for the dynamic similarity of scaled model tests involving local pressures. However, some technical issues in the application of experimental data to actual tank designs are not yet completely resolved. For example, the scaling law from model test data to real ships is not yet clear. Kimmoun et al. (2010) and Bogaert et al. (2010) carried out wave canal tests and the Sloshel project, respectively, in order to see the 
difference of pressure scaling ratio with respect to different model test scaling ratios. As an alternative method, numerical methods have been applied. Many numerical studies on sloshing flows including coupled with ship motions have been reported during last two decades. Some representative works have been introduced by Webster (1967), Dillingham (1981), Rognebakke and Faltinsen (2003), Kim et al. (2007), Kim and Shin (2008). Generally, we can consider two approaches: the frequency-domain approach (e.g., Newman 2005) assuming linear sloshing flow, the time-domain approach adopting nonlinear sloshing flow (e.g., Kim 2002). Although significant progress has been made in the experimental techniques and advanced nonlinear computational methods, they are still very costly and time-consuming to perform; thus, few methods are applicable for actual engineering use, especially the fast simulation of sloshing flows and direct prediction of sloshing severity from a set of sea states. Kim et al. (2010) introduced an energy-based method, and then (Gou et al. 2011) provided related research by using partial kinetic energy to analyze the sloshing severity. Later, Zheng et al. (2013) raised the primary idea and analyzed sloshing severity from both global and local points of view, with a generation of the sloshing severity diagram of a LNG-FPSO case. Furthermore, Zheng et al. (2013) developed superposition methods for wave spectrum, to apply this direct method to sloshing severity diagrams under different loading conditions.

The objective of this paper is to propose an efficient way to identify critical sea states before the sloshing model test campaign, so as to save time and money by focusing on those test conditions that are most likely to produce large sloshing pressures on tank walls. The present study begins with the concept of sloshing severity RAO (SSR), followed by a brief view of the physical problem and the numerical scheme of sloshing flow coupled with ship motion. Since we are dealing the sloshing problem in a linear regime for a fast computation, modifications to the initial SSR are needed. To this end, a 3D regular model test of 1/50 scaling is conducted, and results from experiment are used to get the coefficients of SSR empirical formulation. To validate the current methodology we are using, comparisons on sloshing severity index (SSI) between numerical and experimental results from the same tank but in irregular conditions are presented. Similar tendency can be observed from the results, which means that the severity of sloshing is reasonably estimated in a simple but efficient way. Finally, the fitted new index shall be applied in the wave scatter diagram, in aim to pick up the crucial situations where most severe sloshing may occur among a large set of irregular sea states. Therefore, selection of severe sloshing sea states can be fulfilled and then sloshing loads analysis can be done within a much smaller range of detailed computational fluid dynamics (CFD) simulations or model tests.

\section{Numerical simulation}

\subsection{Sloshing severity RAO}

One factor that contributes to larger sloshing pressures on the tank surface is the violent free surface motion inside the tank. Under this circumstance, the water inside the tank may have more pronounced energy, larger velocity, or higher wave elevation. Thus, for the measurement of sloshing severity, we can define the sloshing severity RAO (SSR) based on identities from either global or local concept. Zheng et al. (2013) came up with a comprehensive introduction to the possible parameters. Figure 1 shows the candidate parameters analyzed so far. Based on those parameters, SSR is evaluated at each wave frequency in regular wave conditions in frequency domain.

To get the above possible parameters contributed to SSR, we start from analysis of ship motion and sloshing.

\subsubsection{Ship motion}

Let us consider a ship equipped with a partially filled tank, moving with a constant velocity $V_{n}$. Two coordinate systems, ship-fixed coordinate (XYZ) and tank-fixed coordinate (xyz) are defined in Fig. 2. The ship-fixed Cartesian coordinate system is defined at the origin $\mathrm{G}$ of excitation motion (typically center of ship motion). The ship is under 6 degree-offreedom motion due to incident waves with heading angle $\beta$. Therefore, ship mass, hydrodynamic coefficients, wave excitation forces, and restoring coefficients are defined with respect to the center of gravity of ship.

The ship motion problem can be solved by several numerical methods, e.g., slender body theory, 3D panel method, and CFD-based computation. In this study, the primary interest is a fast computation, focusing on motion response only. In such case, strip method is chosen as the method of solution.

If a slender body is in low forward speed and high incident wave frequency, hydrodynamic coefficients can be obtained by integrating the sectional solutions. For a 2-D strip, the velocity potential $\phi_{k}$ satisfies the following boundary value problem:

$\nabla^{2} \phi_{k}=0,(k=2,3,4)$ in a fluid domain

$-\omega_{e}^{2} \phi_{k}+g \frac{\partial \phi_{k}}{\partial Z}=0,(k=2,3,4)$ on $Z=0$

$\frac{\partial \phi_{k}}{\partial n}=V_{n},(k=2,3,4)$ on $\mathrm{S}_{b}$ 


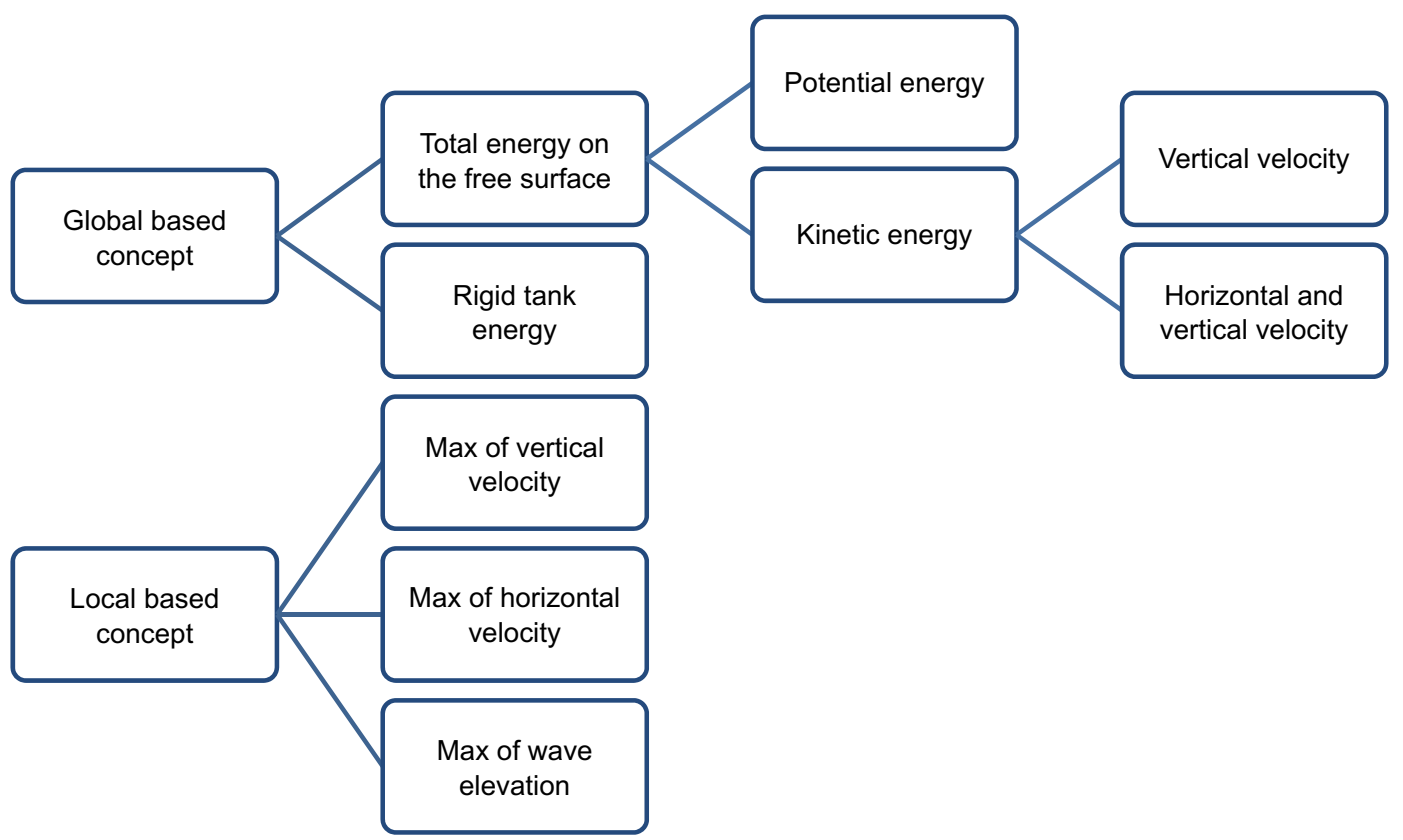

Fig. 1 Candidate parameters for SSR analysis

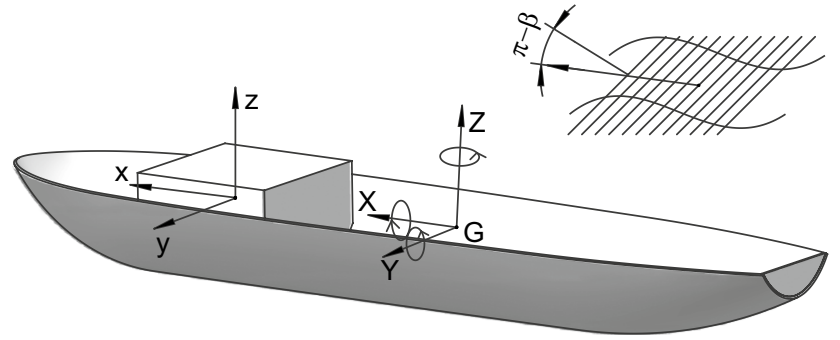

Fig. 2 Definition of the coordinate system

$\lim _{y \rightarrow \infty} \nabla \phi_{k}=0,(k=2,3,4)$

where $k=2$ for sway motion, $k=3$ for heave motion, and $k=4$ for roll motion. $\omega_{\mathrm{e}}$ and $g$ refer to the encounter wave frequency and gravity constant, respectively.

To solve the prescribed two-dimensional boundary value problem, a two-dimensional oscillatory source (wave Green function) is applied, which can be expressed as follows (Newman 1985):

$G_{2}=\left[\log \left(\frac{r}{r_{1}}\right)-2 \int_{0}^{\infty}(k-1)^{-1} \mathrm{e}^{-k Y} \cos (k X) \mathrm{d} k\right] \cos (\omega t)$

$-2 \pi e^{-Y} \cos X \sin (\omega t)$

where $r$ and $r_{1}$ represent the distances from a field point to a source, and an image source with respect to the $Y$-axis, respectively. $X$ and $Y$ are field point values, which are nondimensionalized by the wave number $\omega^{2} / g$.

To implement numerical computation of the wave Green function, the computer codes developed by Sclavounos (1985), NIIRID, are adopted. Using this program, sectional hydrodynamic coefficients and exciting forces can be calculated. In the calculation of ship motion, STF (Salvesen et al. 1970) strip theory is used.

\subsubsection{Sloshing Flow}

Since violent sloshing flow is strongly nonlinear, the analysis of nonlinear sloshing problem can be naturally the first choice for prescreening the sloshing severity. However, the analysis of nonlinear sloshing flow requires significant effort for numerical computation. Therefore, in this study, we start from the application of linear sloshing flow for a fast and efficient prescreening.

Consider the fluid motion inside a partially filled tank (Fig. 2). A tank-fixed coordinate system is defined at the center of the free surface inside the tank. The velocity potential $\Phi$ satisfying the Laplace equation can be determined by (Faltinsen and Timokha 2009):

$\frac{\partial \Phi}{\partial n}=\dot{\Xi} \cdot n_{T}+\dot{A} \cdot\left[r_{T} \times n_{T}\right]$ on $S_{T}$

$\frac{\partial \eta}{\partial t}+\dot{\Xi} \cdot n_{T}+\dot{A} \cdot\left[r_{T} \times n_{T}\right]=\frac{\partial \Phi}{\partial t}$ on $S_{F}$ 
$\frac{\partial \Phi}{\partial t}=g \alpha_{2} x-g \alpha_{1} y-g \zeta$ on $S_{F}$

where $\Xi=\left(\xi_{1}, \xi_{2}, \xi_{3}\right)$ and $A=\left(\alpha_{1}, \alpha_{2}, \alpha_{3}\right)$ are the translations and rotation angles. $r_{T}$ is a position vector, and $\zeta$ is the free surface elevation. Unit normal vector $n_{\mathrm{T}}$ points out from the fluid region. $S_{\mathrm{T}}$ and $S_{\mathrm{F}}$ indicate the mean wetted part of tank wall and undisturbed free surface, respectively.

Under linear assumption in frequency domain, the velocity potential can be decomposed and the time-dependent quantities can be separated as $\Phi=\sum_{j=1}^{6}-i \omega \xi_{j} \phi_{j} e^{-i \omega t}$, thus the boundary conditions can be written as below:

$$
\begin{aligned}
& \frac{\partial \phi_{j}}{\partial n}=n_{j} \\
& n_{j}=\left\{\begin{array}{l}
n_{T} j=1,2,3 \\
r_{T} \times n_{T} j=4,5,6
\end{array} \text { on } S_{T}\right. \\
& \frac{\partial \phi_{j}}{\partial z}-\left(\frac{\omega^{2}}{g}+\frac{i \omega \mu_{1}-\mu_{2}}{g}\right) \phi_{j}=n_{j} \\
& n_{j}=\left\{\begin{array}{l}
1 j=3 \\
0 j \neq 3
\end{array} \text { on } S_{F}\right.
\end{aligned}
$$

where $\phi_{j}(j=1,2, \ldots, 6)$ is the radiation potential in the $j$ th mode, $\omega$ is the angular frequency of tank motion, equal to the wave encounter frequency. $\mu_{1}=2 \omega_{0} \kappa$ and $\mu_{2}=\mu_{1}^{2} / 4$ are introduced to consider the viscous damping on the free surface, and $\omega_{0}$ is the fundamental sloshing resonance frequency (Kim 2003).

By using Green's second identity, the boundary integral equation can be established and velocity potential can be solved easily.

$$
\begin{aligned}
& \alpha \phi_{j}-\iint_{S_{T}} \phi_{j} \frac{\partial G_{3}}{\partial n} \mathrm{~d} s-\iint_{S_{F}} \phi_{j}\left[\frac{\partial G_{3}}{\partial n}-\left(\frac{\omega^{2}}{g}+\frac{i \omega \mu_{1}-\mu_{2}}{g}\right) G_{3}\right] \mathrm{d} s \\
& =-\iint_{S_{T}+S_{F}} G_{3} n_{j} \mathrm{~d} s
\end{aligned}
$$

$G_{3}$ is the Green function given by 3-D Rankine source potential. In this paper, a higher-order boundary element method is used, so the solid angle coefficient $\alpha$ changes with the shape of the body surface. It can be determined by a direct method (Teng et al. 2006). Sloshing-induced force and moment can be obtained by:

$F_{\text {slosh }}=\left[\omega^{2} A_{i j}+i \omega B_{i j}-C_{i j}\right] \xi_{j}$

where $A_{i j}, B_{i j}$ are added mass and radiation damping in the $i$-th mode, $C_{i j}$ the restoring coefficient.

\subsubsection{Coupled analysis of sloshing and ship motion}

The ship motion coupled with sloshing can be identified by the rigid-body motion equation

$[M]\{\ddot{\xi}\}=\left\{F_{\text {ext }}\right\}+\left\{F_{\text {slosh }}\right\}$

Here, $[M]$ represents the ship mass matrix including liquid mass in tanks. The subscripts ext and slosh mean the components due to external incident wave and sloshing flow inside tank, respectively. The both force matrixes can be expressed by using hydrostatic and hydrodynamic coefficients. Therefore, the resulting equation of motion for shipsloshing coupling in frequency domain can be derived as shown in Eq. (14).

$\left\{\begin{array}{l}-\omega^{2}\left([M]+[A]_{\mathrm{ext}}+[A]_{\mathrm{slosh}}\right) \\ -i \omega\left([B]_{\mathrm{ext}}+[B]_{\mathrm{slosh}}\right)+ \\ \left([C]_{\mathrm{ext}}+[C]_{\mathrm{slosh}}\right)\end{array}\right\}\{\xi\}=\left\{F_{\mathrm{ex}}\right\}$

Here, $\left\{F_{\text {ex }}\right\}$ denotes the excitation forces induced by incident waves such as Froude-Krylov force and diffraction force. To include viscous roll damping, an equivalent linear damping coefficient is used as

$B_{44}=2 \gamma \sqrt{\left(M_{44}+A_{44, \infty}\right) C_{44}}$

where $M_{44}, A_{44, \infty}$ and $C_{44}$ represent mass moment of inertia, infinite-frequency added moment of inertia, and restoring coefficient of roll motion, respectively. Besides, $\gamma$ indicates a ratio to the critical roll damping and is generally in the range of $0.05-0.1$.

\subsubsection{Concept of SSR}

In this study, one typical local-based parameter, maximum wave elevation on the free surface, is chosen as the initial index to present sloshing severity. For each wave frequency at a certain direction of the tank motion, we get the rough estimation by the following equation:

$\operatorname{SSR}(\omega)=\operatorname{Max}\{\eta(\omega)\}$

When the SSR is computed for all filling levels $(10 \% \mathrm{H}$, $15 \% \mathrm{H}, 30 \% \mathrm{H}, 50 \% \mathrm{H}, 70 \% \mathrm{H}, 90 \% \mathrm{H}, 95 \% \mathrm{H}$ ) and 4 directions of motions (surge, sway, roll, pitch), the normalization is conducted with respect to the maximum SSR value, noted as $\operatorname{SSR}_{\text {initail }}(\omega)$. Since sloshing phenomena is quite nonlinear, the above initial index from linear computations cannot give a good prediction. Thus, by comparing with data from the model test, modification coefficients have to be added so that part of nonlinearity (e.g., softening and hardening) can be included in the new index. 
$\operatorname{SSR}_{\text {new }}\left(\frac{\omega}{\omega_{0}}\right)=l \times \operatorname{SSR}_{\text {initial }}\left(m \frac{\omega}{\omega_{o}}+n\right)$

where $l, m$ and $n$ are fitting coefficients in the empirical formulation. Compared with average of 10 largest impulse areas from experiment, $l, m$ and $n$ can be calculated under a certain filling level and certain excitation amplitude, by using the nonlinear least square method. After fitting a 3D LNG tank in regular cases, obtained coefficients and corresponding $\mathrm{SSR}_{\text {new }}$ will be used for irregular analysis.

\subsection{Sloshing severity index}

In the regular cases, model tests are conducted under a set of single-degree-of-freedom (SDOF) motions. In reality, LNG tanks in LNG carriers move in 6 degree-offreedom (6-DOF). Therefore, the nonlinear superposition is applied to the case of multi-DOF motions, which gives the motion-superposed sloshing severity RAO (MSSR) (Zheng et al. 2014).

$\operatorname{MSSR}(\omega)=\sqrt{\sum\left(\operatorname{SSR}_{\text {new }, j} \times \xi_{T, j}\right)^{2}}$

Here, $\mathrm{SSI}_{\text {new }, j}$ is the modified index under unit tank motion, and $\xi_{T, j}$ the tank motion amplitude in the $j$-th mode, obtained from ship motion RAO, either coupled or uncoupled with sloshing. One thing needs to be mentioned is that $\mathrm{SSI}_{\text {new }, j}$ can be calculated based on either small-amplitude or large-amplitude regular test results. We note the corresponding MSSR as $\operatorname{MSSR}_{s}$ and MSSR .

Considering the irregular waves with a given wave spectrum, there are two types of superposition methods as shown in Eqs. (19) and (20):

$\operatorname{SSR}_{1}=\int_{0}^{\infty} \sqrt{2 s(\omega) \mathrm{d} \omega} \times \operatorname{MSSR}(\omega)$

$\operatorname{SSR}_{2}=\operatorname{Max}\{\sqrt{2 s(\omega) \mathrm{d} \omega} \times \operatorname{MSSR}(\omega)\}$

For easy comparison with experiment data, normalized sloshing severity is calculated from the ratio of each SSR value to the maximum, noted as $\operatorname{SSR}_{\max }$ :

$\mathrm{SSI}=\frac{\mathrm{SSR}}{\mathrm{SSR}_{\max }}$

In conclusion, four types of SSI values can be calculated, and user can pick the most appropriate value depending on the conditions of calculation. The notation of each SSI value is described in Table 1. The flowchart for calculating sloshing severity index can then be summarized as Fig. 3.
Table 1 The notation for SSI

\begin{tabular}{ll}
\hline Notation & Description \\
\hline $\mathrm{SSI}_{1}$ & $\mathrm{Using} \mathrm{MSSR}_{s} \& \mathrm{SSR}_{1}$ \\
$\mathrm{SSI}_{2}$ & $\mathrm{Using} \mathrm{MSSR}_{s} \& \mathrm{SSR}_{2}$ \\
$\mathrm{SSI}_{3}$ & $\mathrm{Using} \mathrm{MSSR}_{l} \& \mathrm{SSR}_{1}$ \\
$\mathrm{SSI}_{4}$ & Using MSSR $\& \mathrm{SSR}_{2}$ \\
\hline
\end{tabular}

\section{Model test}

\subsection{Experiment setup}

Both regular and irregular model tests on a 1:50 scaled LNG tank are considered. Model tests are carried out at the sloshing experimental facility at Seoul National University (SNU). Figure 4 shows a simplified schematic diagram of the measurement system for the sloshing experiment. The motion platform, shown in Fig. 5a, makes the model tank perform 6 degree-of-motion. Then pressure sensors, which are installed in the tank, measure the dynamic pressure on the tank wall. A data acquisition system converts electric pressure data into digital data. The acquired data is monitored in real-time and saved into a data storage server.

\subsection{Test conditions}

\subsubsection{D regular test}

The 3D tank considered in this experiment is a prismatic tank as shown in Fig. 5b. This tank has a dimension of $0.8682 \mathrm{~m}(\mathrm{~L}) \times 0.76 \mathrm{~m}(\mathrm{~B}) \times 0.566 \mathrm{~m}(\mathrm{H})$ and its shape is from a $145 \mathrm{~K}$ LNGC. Seven filling levels $(10 \% \mathrm{H}, 15 \%$ $\mathrm{H}, 30 \% \mathrm{H}, 50 \% \mathrm{H}, 70 \% \mathrm{H}, 90 \% \mathrm{H}, 95 \% \mathrm{H})$ and $4 \mathrm{regu}-$ lar motions (surge, sway, pitch, and roll) were considered. As is mentioned before, there are 2 amplitudes for each motion, small $\left(3 \% \mathrm{~L}, 5 \% \mathrm{~B}, 3^{\circ}\right)$ and large $(6 \% \mathrm{~L}, 10 \% \mathrm{~B}$, $6^{\circ}$ ). For each regular case, more than 10 frequencies near the resonance frequency were tested. Besides, 500 cycles of each motion were selected as the time window. Based on the measured sloshing peaks, average of 10 largest impulse areas are compared with numerical results.

\subsubsection{D irregular test}

Two sets of irregular tests, referred as FY1 and FY2, were conducted using the same 3D tank. ITTC spectrum was used to simulate irregular waves. Sea states considered in the tests, given by zero-crossing period $T_{\mathrm{z}}$, and significant wave height $H_{\mathrm{s}}$, are listed in Tables 2 and 3. In this experiment, uncoupled motion RAO with 5 knots forward speed was used to generate tank motion signals in both ballast and full loading conditions. With a Froude scaling, model 


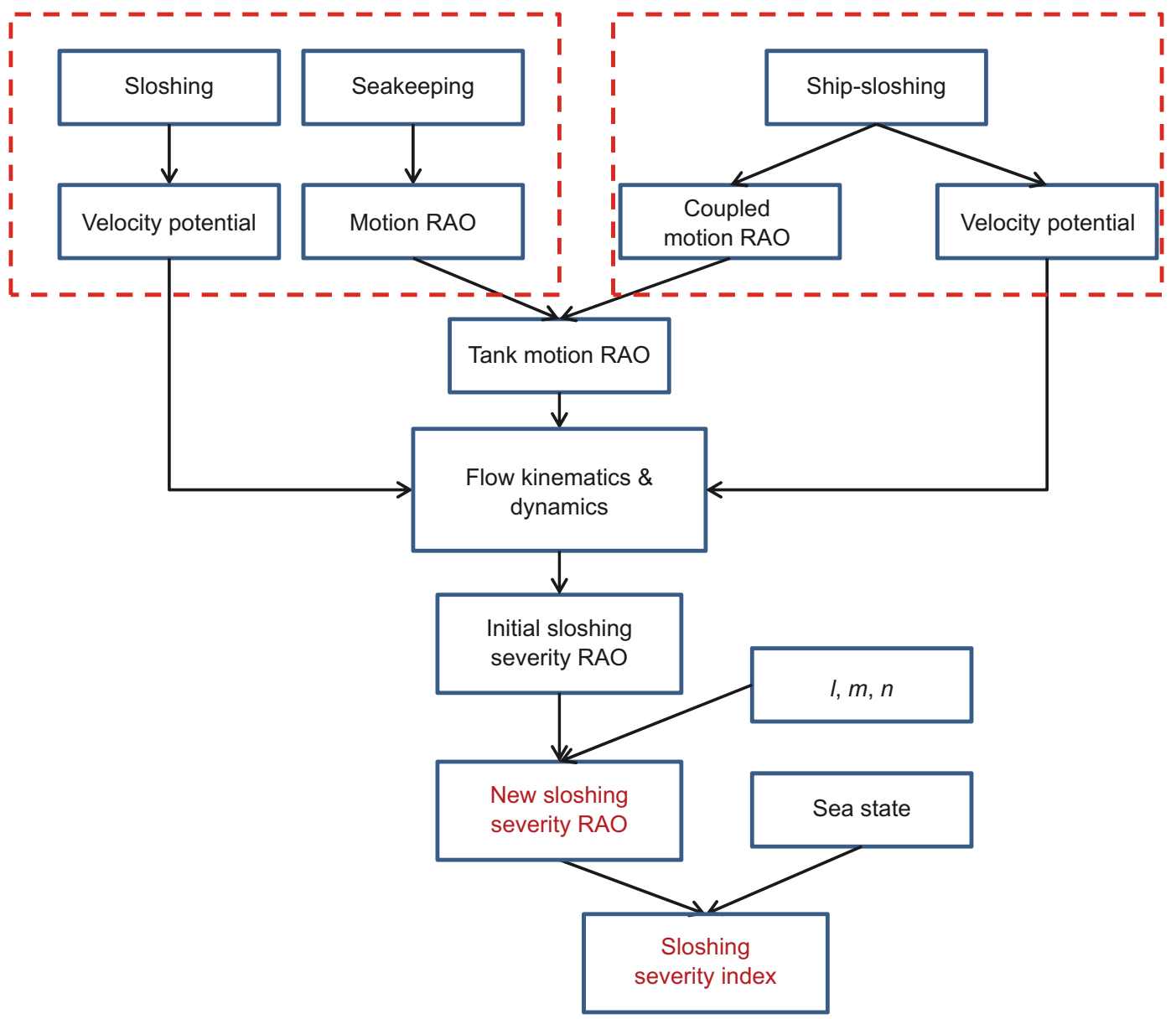

Fig. 3 Procedure of sloshing severity index prediction

tests were taken for around $43 \mathrm{~min}$, corresponding to a 5-h simulation in real scale (Kim et al.2013).

\section{Results and discussion}

To validate the usability of this methodology, a LNGFPSO is considered. By comparing results from stripcoupling program with experimental and other numerical results, we can see that the current coupling program is ready to use. Then, some selected numerical results of sloshing severity index are compared with the average of 10 largest peak pressure and impulse area from sloshing model test. Finally, an application case to a real ship with International Association of Classification Societies (IACS) wave spectrum is presented, using both coupled and uncoupled ship motion. The concept of SSI diagram keeps the consistence with the primary intention of introducing sloshing severity index.

\subsection{Coupling validation}

A LNG-FPSO with two tanks is considered. Towing-tank experiment for 1/100 scale model has been carried out at Seoul National University (Nam et al. 2009). In the experiment, only heave, roll and pitch motions are allowed. Table 4 gives the main dimensions of the hull and tanks.

Figure 6 shows the motion RAOs of the LNG-FPSO in beam sea condition with $20 \% \mathrm{H}$ filling. Here, Exp. represents experiment data; WISH (Wave-Induced SHip motion and loads) is the calculation from a computer program developed by Seoul National University; WAF is obtained by using a 3D wave Green function; Strip is the result from current coupling program. From the comparison, it can be seen that not only the numerical computations show a similar tendency with experimental data, but also the three numerical results have a good agreement with each other. Thus, the current method can be used to do coupling analysis. 


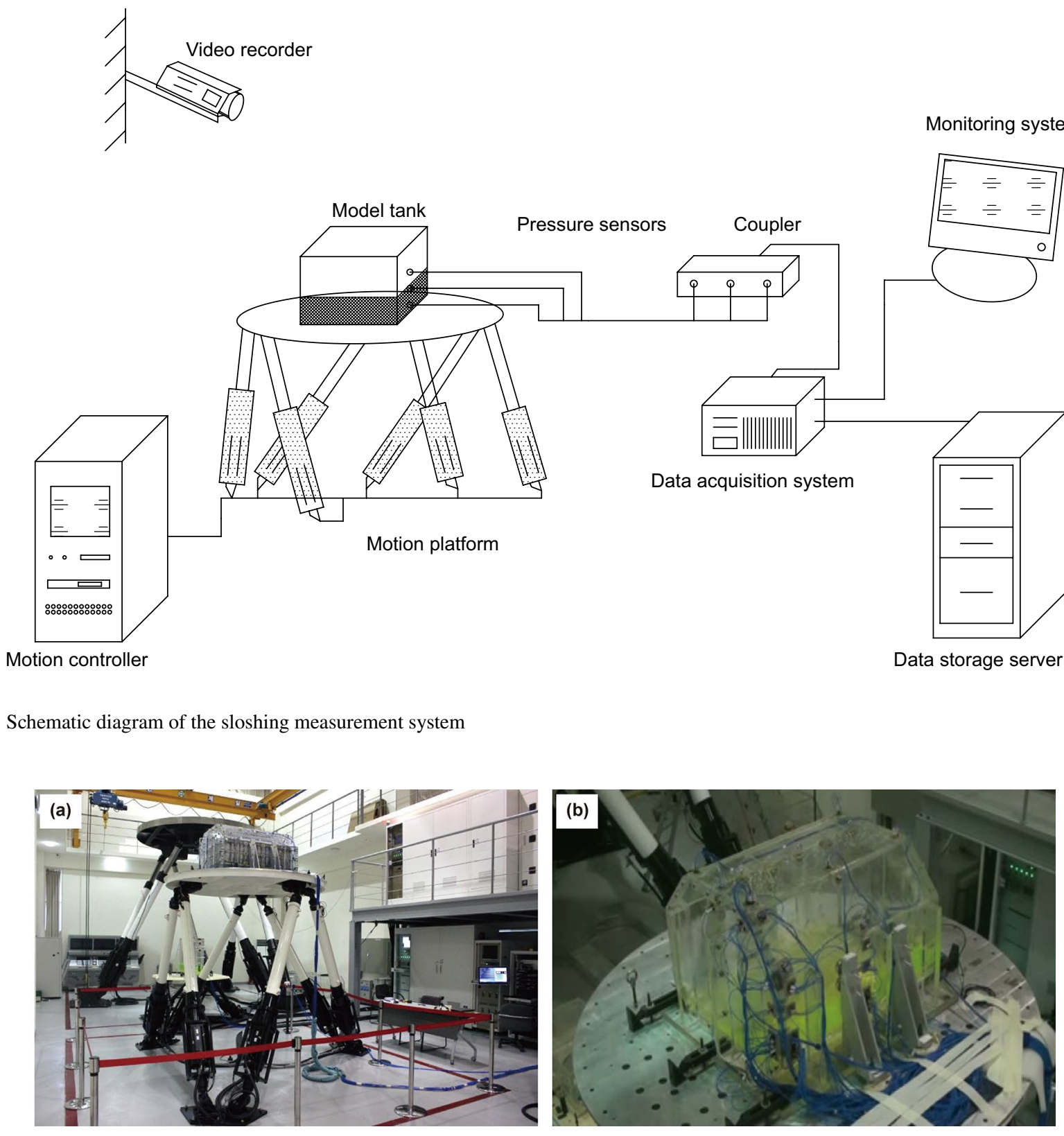

Fig. 5 Sloshing experiment in SNU a Motion platform, b Snapshot of 3D tank

Table 2 FY1irregular sea states (Total: 35 cases)

\begin{tabular}{|c|c|c|c|c|c|c|}
\hline Filling level, \% H & $H_{\mathrm{s}}, m$ & $T_{\mathrm{z}}, \mathrm{s}$ & Heading, ${ }^{\circ}$ & $H_{\mathrm{s}}, \mathrm{m}$ & $T_{\mathrm{z}}, \mathrm{s}$ & Heading, ${ }^{\circ}$ \\
\hline \multirow[t]{5}{*}{$95,70,50$} & 7.3 & 6 & 150 & 15.5 & 13.5 & 150 \\
\hline & 11.1 & 7.5 & 150 & 14.5 & 15.0 & 150 \\
\hline & 13.8 & 9.0 & 150 & 15.5 & 13.5 & 150 \\
\hline & 15.2 & 10.5 & 150 & 14.5 & 15 & 150 \\
\hline & 15.8 & 12.0 & 150 & & & \\
\hline \multirow[t]{4}{*}{30,15} & 5 & 6 & 90 & 12 & 12 & 90 \\
\hline & 8.3 & 7.5 & 90 & 11 & 13.5 & 90 \\
\hline & 10.6 & 9 & 90 & 7.4 & 15 & 90 \\
\hline & 11.8 & 10.5 & 90 & & & \\
\hline
\end{tabular}


Table 3 FY2 irregular sea states (total: 46 cases)

\begin{tabular}{|c|c|c|c|c|c|c|}
\hline Filling level, \% $\mathrm{H}$ & $H_{\mathrm{s}}, \mathrm{m}$ & $T_{\mathrm{z}}, \mathrm{s}$ & Heading, $^{\circ}$ & $H_{\mathrm{s}}, \mathrm{m}$ & $T_{\mathrm{z}}, \mathrm{s}$ & Heading, ${ }^{\circ}$ \\
\hline \multirow[t]{6}{*}{90,50} & 3.5 & 6 & 150 & 11.5 & 10.5 & 150 \\
\hline & 7.3 & 6 & 150 & 15.2 & 10.5 & 150 \\
\hline & 3.5 & 7.5 & 150 & 7.5 & 13.5 & 150 \\
\hline & 7.5 & 7.5 & 150 & 11.5 & 13.5 & 150 \\
\hline & 11.1 & 7.5 & 150 & 15.5 & 13.5 & 150 \\
\hline & 3.5 & 10.5 & 150 & 7.5 & 15 & 150 \\
\hline \multirow[t]{5}{*}{30,15} & 5 & 6 & 90 & 9.5 & 10.5 & 90 \\
\hline & 3.5 & 7.5 & 90 & 11.8 & 10.5 & 90 \\
\hline & 8.3 & 7.5 & 90 & 3.5 & 13.5 & 90 \\
\hline & 3.5 & 10.5 & 90 & 7.5 & 13.5 & 90 \\
\hline & 5.5 & 10.5 & 90 & 11 & 13.5 & 90 \\
\hline
\end{tabular}

Table 4 Main particulars of LNG-FPSO and tanks

\begin{tabular}{llll}
\hline LNG-FPSO & Tank & & \\
\hline Length between perpendiculars $(L), \mathrm{m}$ & 285.0 & FP tank & AP tank \\
Breadth molded on water line $(B), \mathrm{m}$ & 63.0 & Length, $\mathrm{m}$ & 59.68 \\
Draught $(T), \mathrm{m}$ & 13.0 & Breadth, $\mathrm{m}$ & 46.92 \\
Displacement volume molded $(\nabla), \mathrm{m}^{3}$ & $220,017.6$ & Height, $\mathrm{m}$ & 32.23 \\
Radius of gyration $\left(K_{\mathrm{xx}}, K_{\mathrm{yy}}\right), \mathrm{m}$ & $19.45 ; 71.25$ & & 32.92 \\
Center of mass $\left(K_{\mathrm{G}}\right), \mathrm{m}$ & 16.5 & & \\
\end{tabular}
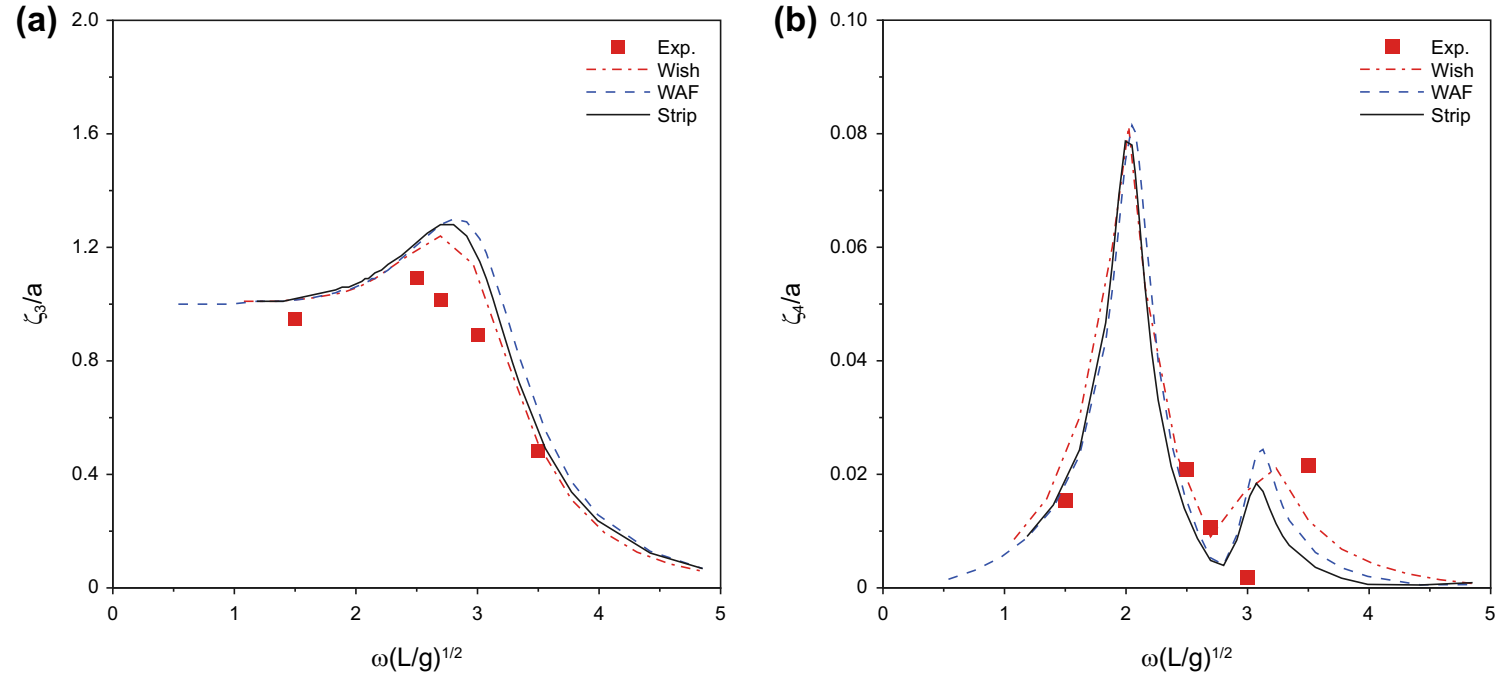

Fig. 6 Motion RAO with $20 \% \mathrm{H}$ filling condition, $90^{\circ}$ heading a Heave RAO (m/m), b Roll RAO (rad/m)

\subsection{Results of 3D regular test}

Since there are many candidate parameters that can be used to present sloshing severity, more suitable parameters are selected based on previous studies and comparisons: average of 10 largest rise-time impulse areas from experiment (in
Figs. 7, 8 and 9 noted as Exp.) and maximum wave elevation (noted as initial) from numerical calculation. Of course, due to the linear computation, initial index cannot give an ideal agreement with experiment results. Thus, with the application of nonlinear least square method, the initial index is modified within each case, as shown in Eq. 17, and then a 

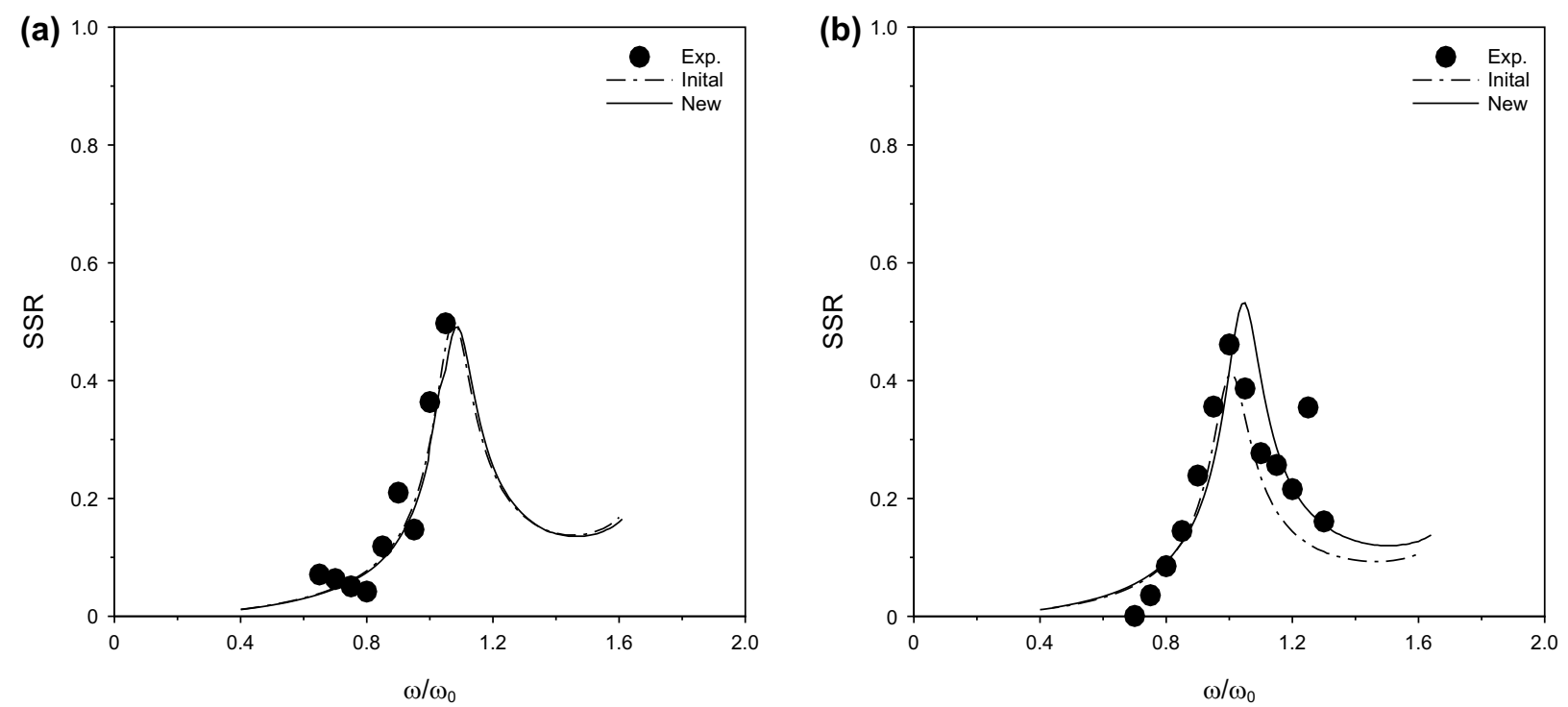

Fig. 7 Sway motion, SSR comparison (Ampl. $=5 \%$ B) a $l=1.29, m=1.00, n=-0.04$
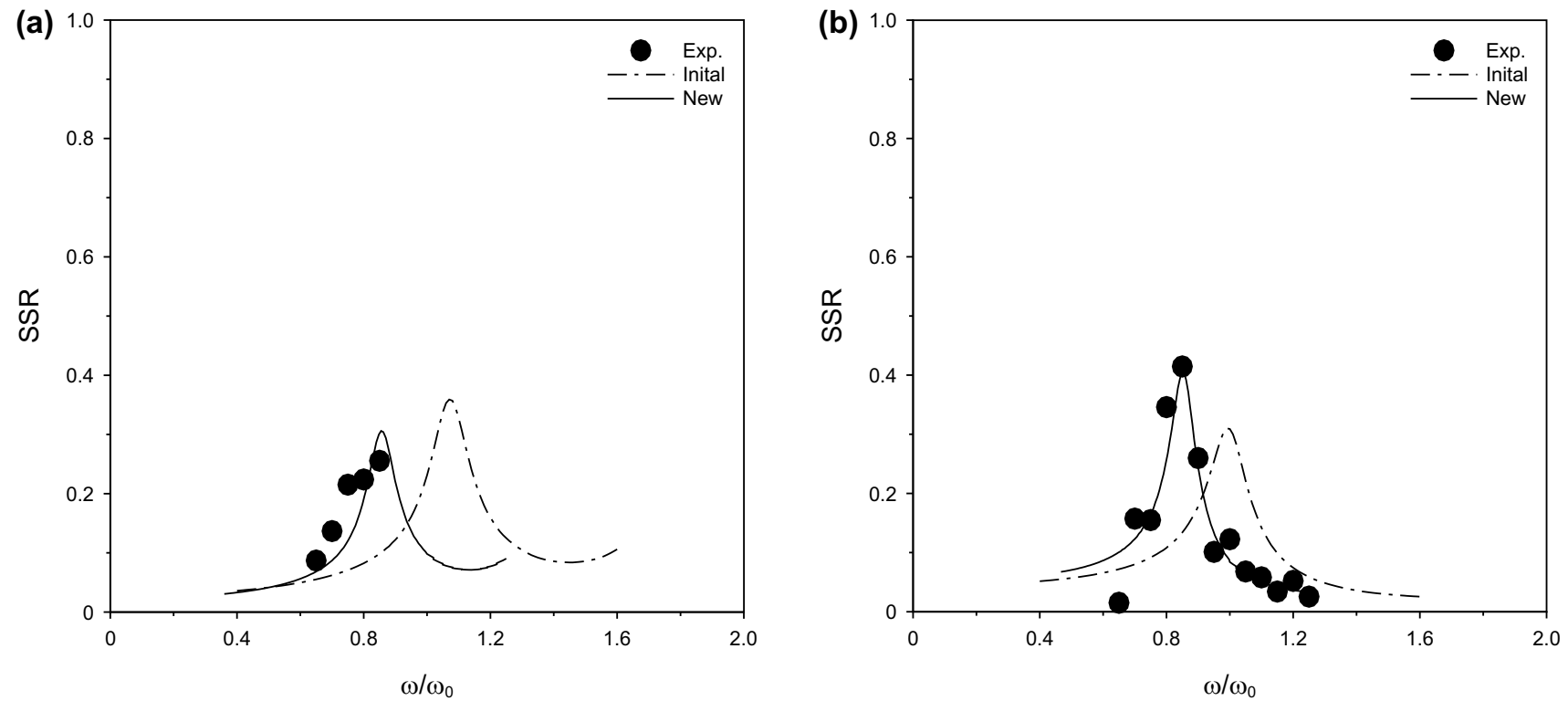

Fig. 8 Roll motion, SSR comparison $\left(\right.$ Ampl. $\left.=6^{\circ}\right)$ a $95 \%$ $l=1.31, m=1.54, n=-0.32$

new index (noted as new) is generated by adding empirical coefficients.

Figures 7, 6 and 9 give examples of the SSR comparison of the 3D tank under regular motions. The $x$-axis is the ratio of excitation frequency to the resonance frequency, and $y$-axis the normalized SSR value. Among all of the regular comparisons, there are some cases where initial index can roughly agree well with experiment data, so that the modification could be very small, such as Fig. 7a, b.

However, with most cases, linear estimation is not enough to predict sloshing severity. Due to the strong nonlinearities in sloshing phenomena, sloshing peak values normally occur around resonance frequency rather than itself. Under such circumstance, modification coefficients are provided for each case. It is easy to tell that this simple modification can make up disadvantages in linear results to some extent. With the new SSR, which has a better correlation with 


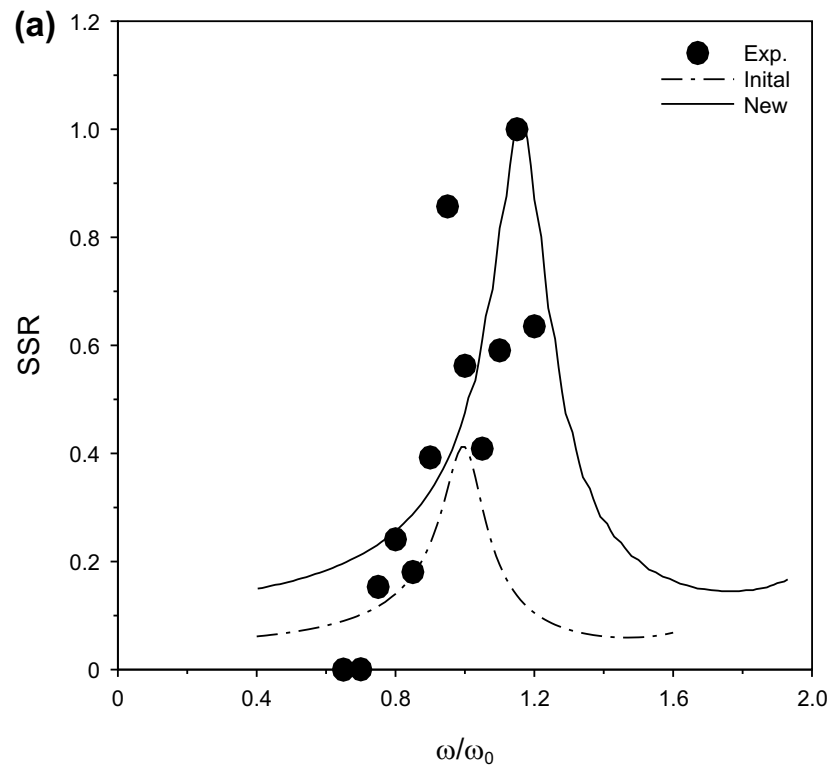

Fig. 9 Pitch motion, SSR comparison (Ampl.=6 deg) a $l=1.31, m=1.54, n=-0.32$

experiment data, we can move on to the next step, namely, sloshing severity prediction under irregular sea conditions.

\subsection{Results of 3D irregular test}

\subsubsection{FY1 \& FY2 results}

\subsubsection{Discussions}

In FY1 irregular model test, 5 filling levels with total 35 cases are analyzed. In each filling level, there are 7 sea states, and each zero-crossing period corresponds to one significant wave height. In FY2 irregular model test, 4 filling levels with total 46 cases are analyzed. In each filling level, sea state combinations are wider, one zero-crossing period corresponding to different significant wave heights. All 4 methods of sloshing severity calculation $\left(\mathrm{SSI}_{1}-\mathrm{SSI}_{4}\right)$ are used, and results are compared with both peak pressure and impulse area from experiment. To avoid tedious charts, selective comparison results based on peak pressure and impulse area are listed, respectively, for FY1 and FY2.

For a better and easier observation, in Figs. 10, 11 we present our results with "error bar", which is the difference between SSI values from numerical and experiment results, $\mathrm{SSI}_{\text {num }}-\mathrm{SSI}_{\text {exp }}$. Here, $x$-axis shows different sea states in each filling level, including heading angle, $T_{\mathrm{z}}$ and $H_{\mathrm{s}} ; y$-axis shows how much the difference is between numerical results and experimental data. Since results of both FY1 and FY2

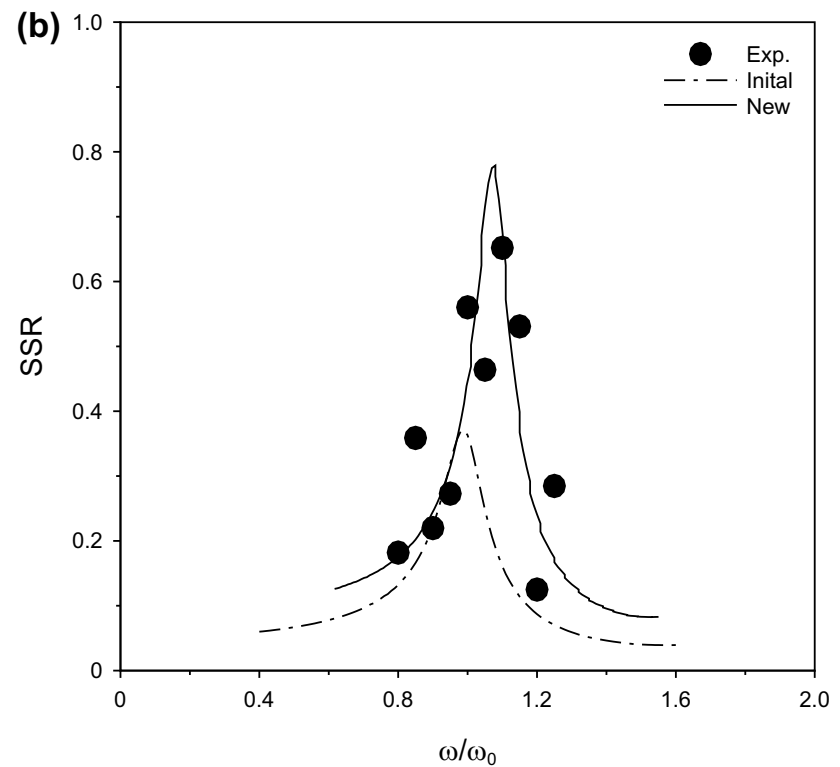

$70 \% \quad \mathrm{H} \quad$ filling, $l=1.02, m=1.35, n=-0.09, \quad$ b $\quad 50 \% \quad \mathrm{H} \quad$ filling,

give a very similar trend, discussions could be put together for simplification.

Figure 10 chooses $\mathrm{SSI}_{\text {pressure, }}$, average of 10 largest peak pressures as the index from experiment; while Fig. 11 chooses $\mathrm{SSI}_{\text {area }}$, average of 10 largest rise-time impulse areas. Figures 10a and 11a apply results from small-amplitude regular test when $\mathrm{SSR}_{\text {new }, j}$ is calculated, while Figs. 10b and $11 \mathrm{~b}$ large amplitude test. One thing for sure is that we want to make the error bar as shorter as possible. Obviously, from both figures we can see that SSI given in (b) is better than those in (a), that is to say, modified index gives more reliable results from large amplitude rather than small one, compared with either peak pressure or impulse area from experiment.

To analyze the preference of two methods applied to wave spectrum shown in Eqs. (19) and (20), direct comparisons between $\mathrm{SSI}_{\text {num }}$ and $\mathrm{SSI}_{\text {exp }}$ are shown in Fig. 12. Actually, from physical point of view, the first method $\mathrm{SSR}_{1}$ is the area under MSSR spectrum, and the second method $\mathrm{SSR}_{2}$ the peak point of the curve. Each method has its own meaning. It is easy to see that $\mathrm{SSI}_{3}$ and $\mathrm{SSI}_{4}$ give quite similar prediction, and both are acceptable. Although $\mathrm{SSI}_{4}$ gives a relatively better prediction in $50 \% \mathrm{H}$ condition, for more severe cases in $30 \% \mathrm{H}$ condition (large $\mathrm{SSI}$ ), $\mathrm{SSI}_{3}$ could successfully filter the most 2 severe cases.

Since we aim at finding the possible severe sloshing situations, it is not difficult to say that for the time being, $\mathrm{SSI}_{3}$ is the best choice, according to the above 2 sets of irregular model tests. Next, $\mathrm{SSI}_{3}$ will be used to real ship application. 

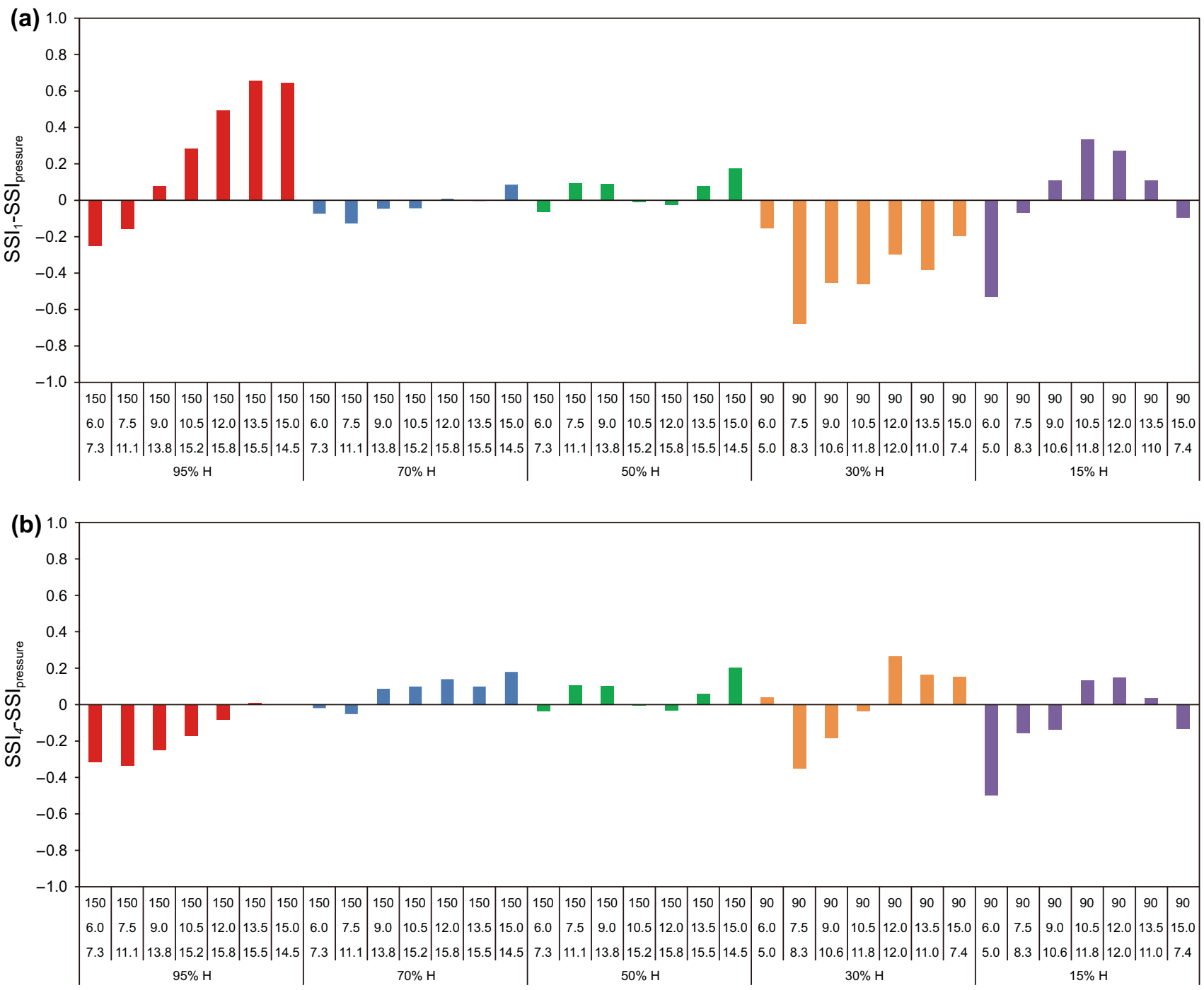

Fig. 10 Selective FY1 SSI comparison with peak pressure a Comparison between $\mathrm{SSI}_{1}$ and $\mathrm{SSI}_{\text {pressure }}$, b Comparison between $\mathrm{SSI}_{4}$ and $\mathrm{SSI}_{\text {pressure }}$

\subsection{Real ship application}

The LNG-FPSO considered here is same with the one used in previous coupling validation. Only the tank length is changed with the increase in tank number from 2 to 5, while the tank height and breadth keeping all the same. Main dimensions are shown in Fig. 13.

Loading and unloading procedures are assumed simultaneously at all five tanks for simplification. Here, both uncoupled and coupled conditions (20\% H filling) are analyzed using the strip method. Those obtained 6-DOF motion RAOs in beam sea condition will be used for later SSI scatter analysis, which will be discussed afterward.

From Fig. 14, it can be easily seen that the roll motion RAO differs between uncoupled and coupled situations. Not only the peak value decreases, but also the resonance shifts to a lower frequency due to liquid sloshing inside tanks, which also gives a second peak in a higher frequency. This may make difference to final results of sloshing severity.

Among five tanks, the one near the ship stern is chosen as the objective tank of sloshing severity analysis. By adopting SSR $_{\text {new }}$, Fig. 15 shows MSSR calculated based on both uncoupled and coupled motion RAOs in regular waves. Due to the difference of motion RAOs, MSSR also differs at peak value and resonance frequency. Since multi-degree-freedom is considered, MSSR curve may contain more than one peak.

In this paper, the wave statistics of IACS North Atlantic wave scatter diagram, which provides the probability or number of occurrences of sea states in a specified ocean, is applied to calculate irregular sloshing severity index. The probability of each sea state is given in terms of occurrences among 100,000 occasions (American Bureau of Shipping 2006), shown in Table 5. 

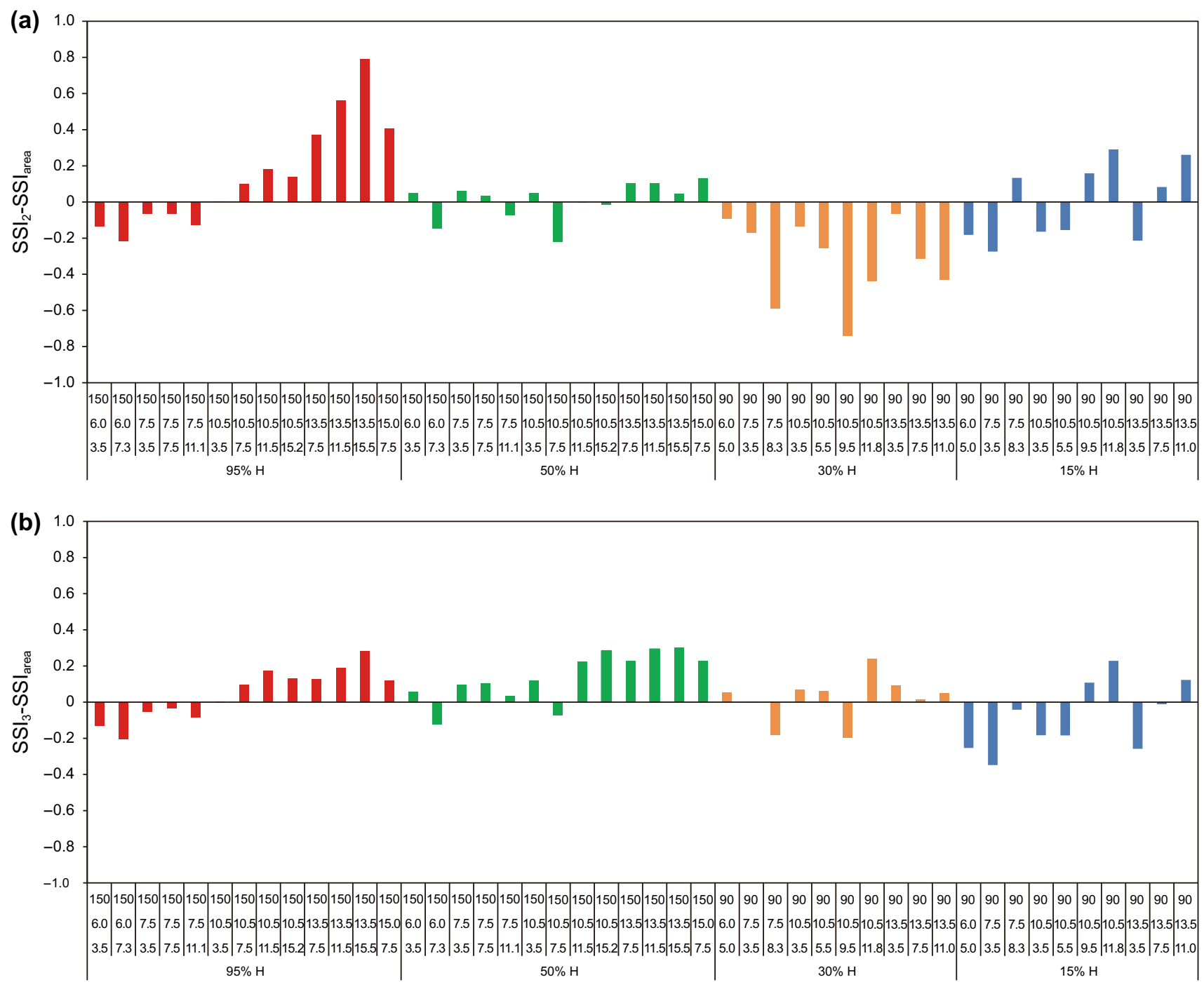

Fig. 11 Selective FY2 SSI comparison with impulse area a Comparison between $\mathrm{SSI}_{2}$ and $\mathrm{SSI}_{\text {area }}$, b Comparison between $\mathrm{SSI}_{3}$ and $\mathrm{SSI}_{\text {area }}$

In most studies, uncoupled motion RAO is used in sloshing experiments. However, the coupled motion RAO may give a different view of sloshing severity. In order to give a more obvious insight to the big difference of SSI by using uncoupled and coupled results, SSI diagrams based on $\mathrm{SSI}_{3}$ are shown as above tables. Here, SSI is normalized by the maximum value from both uncoupled and coupled ones, in order to show the difference of the absolute value between two diagrams. SSI values in Tables 6 and 7 are quite different, showing that in this case, the coupled motion RAO does effect on the calculated sloshing severity by increasing its value. Actually, it is easy to see that in Fig. 15, both $\mathrm{MSSR}_{s}$ and MSSR $\mathrm{M}_{l}$ values based on uncoupled motion RAO are smaller than those based on coupled motion RAO, which leads to the increase of final SSI.

\section{Concluding remarks}

In this paper, sloshing severity index is come up with, tested and developed. In order to get a more accurate form, empirical coefficients are added to the initial index. By applying several different combination methods in regular and irregular waves, numerical results are compared with experimental data. After choosing the best method, the SSI diagram of a LNG-FPSO is generated. Based on the present study, some conclusions can be drawn as follows:

1. This paper provides a numerical program of ship motion coupled with sloshing; 

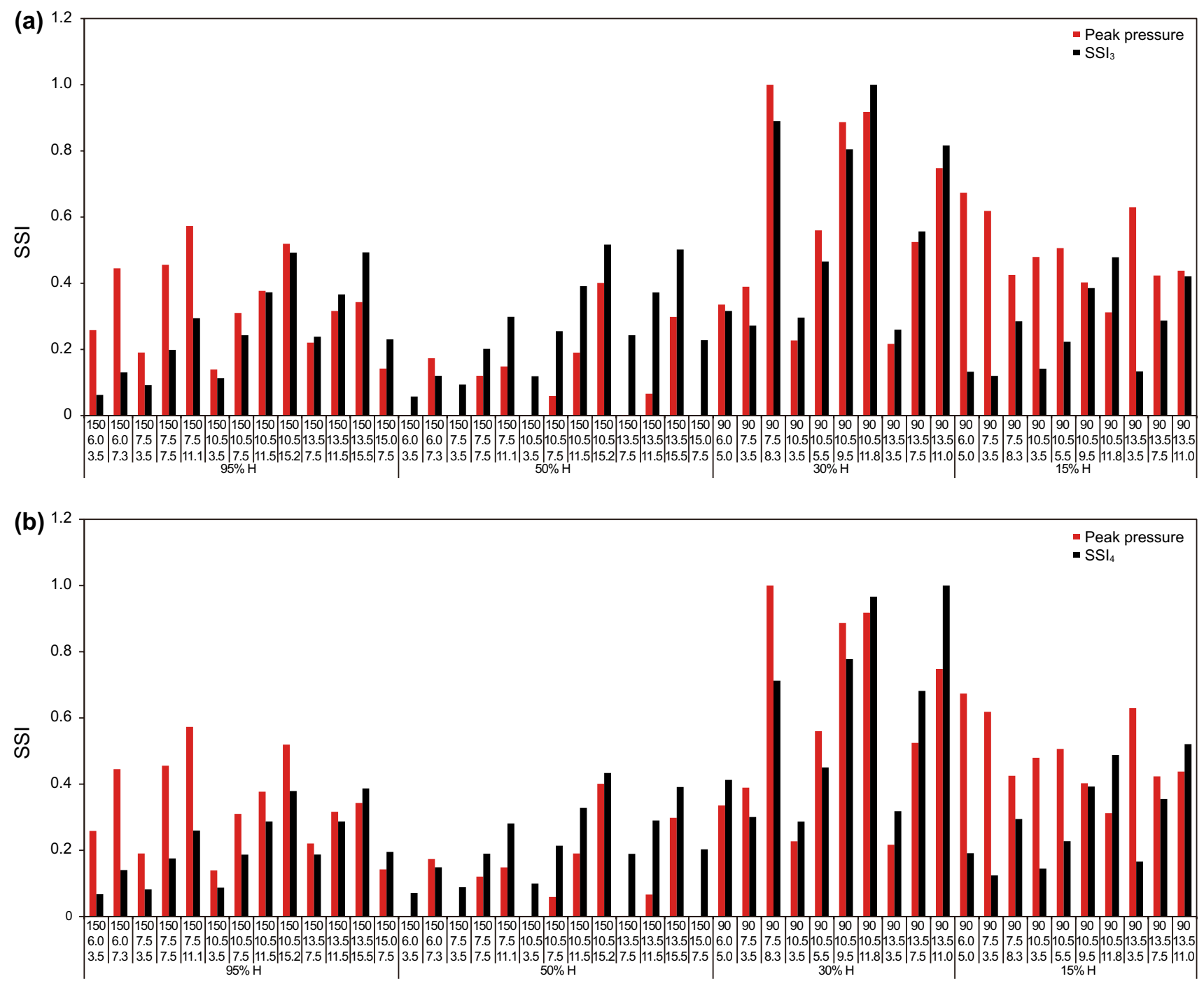

Fig. 12 FY2 SSI direct comparison a Comparison between $\mathrm{SSI}_{3}$ and $\mathrm{SSI}_{\text {pressure }}$, b Comparison between $\mathrm{SSI}_{4}$ and $\mathrm{SSI}_{\text {pressure }}$
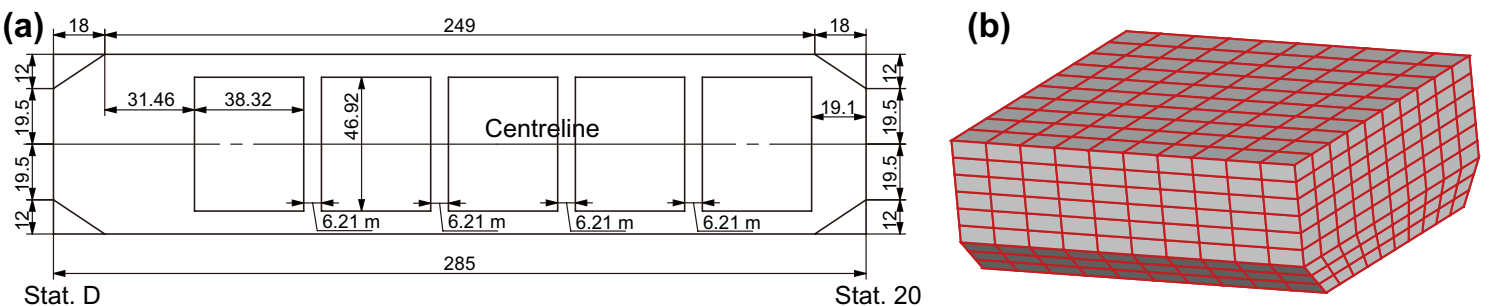

Fig. 13 LNG-FPSO model with 5 tanks a Main dimensions of LNG-FPSO with 5 tanks (unit: m), b Computational panels of one tank

2. This paper provides a numerical program of ship motion coupled with sloshing;

The linear results of SSI in regular test can give a reasonable prediction in some cases, while show large discrepancy with experimental results in most cases. Modification of the initial index is necessary and appli- cable. With simple empirical coefficients, nonlinearities can be added to the initial index, which gives the new index;

3. The results of SSI comparison from 2 sets of 3D irregular model tests show that $\mathrm{SSI}_{3}$ is the best choice for predicting sloshing severity in irregular sea states; 

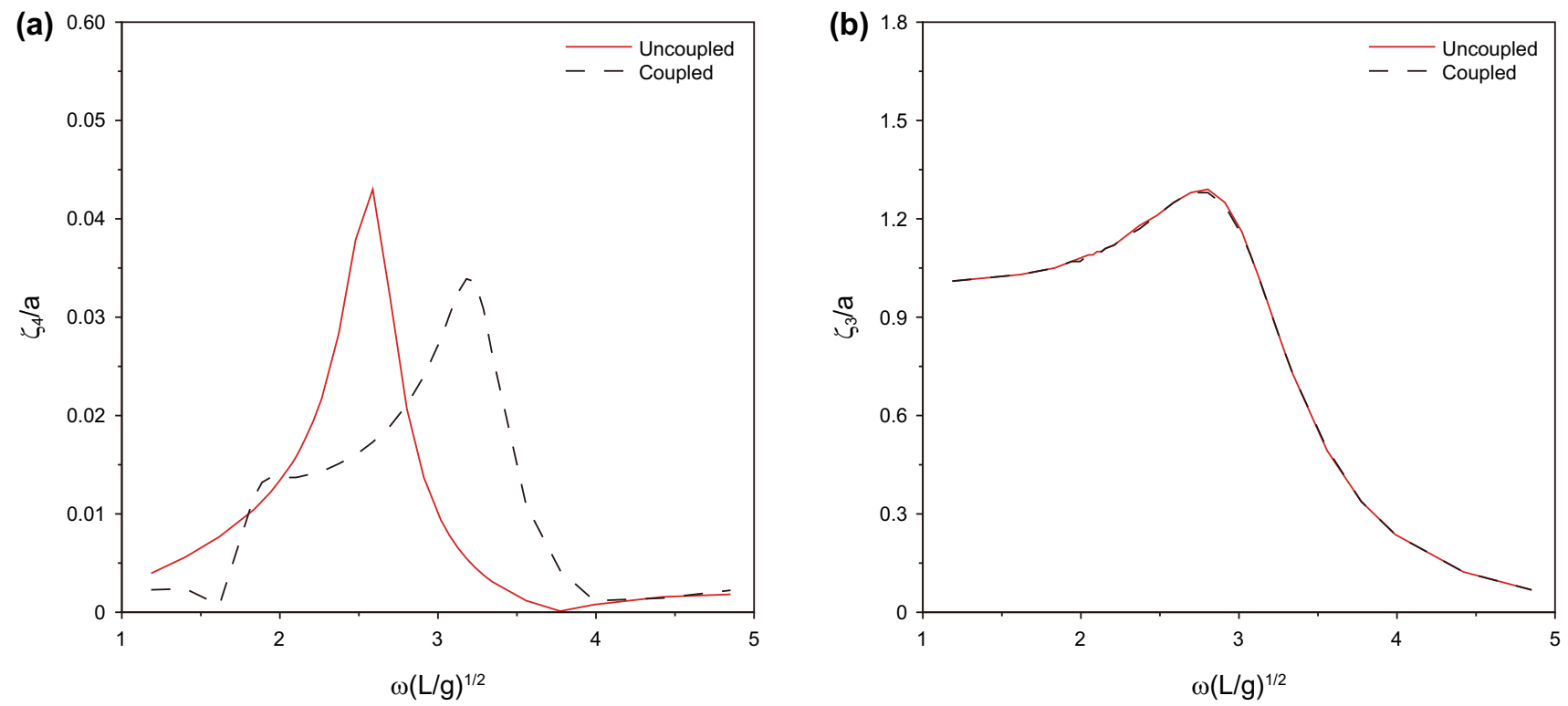

Fig. 14 Motion RAO with and without sloshing, 20\% $\mathrm{H}$ filling, $90^{\circ}$ heading a Heave RAO (rad/m), b Roll RAO (rad/m)
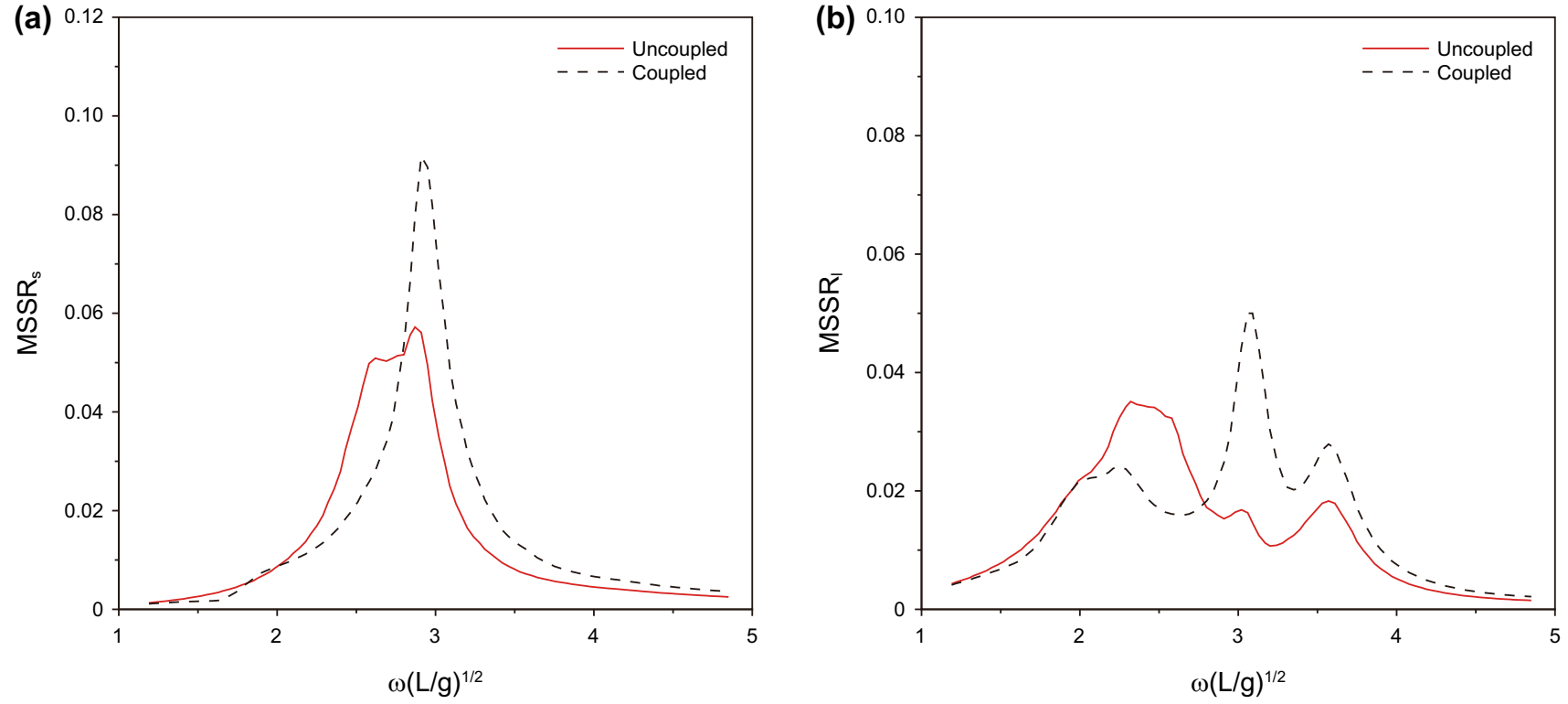

Fig. 15 Motion superposed SSR with and without sloshing, $90^{\circ}$ heading a $\mathrm{MSSR}_{s}, \mathbf{b} \mathrm{MSSR}_{l}$

4. Application to a LNG-FPSO with 5 tanks shows that uncoupled or coupled motion RAOs affect final SSI scatter diagram.

From the current study, it is expected that the generated empirical coefficients can be used to other LNG tanks with similar shapes. By following the same process from regular calculation to irregular estimation, the sloshing severity can be predicted in a fast and efficient way. Therefore, the proposed methodology presenting sloshing severity can be used as a prescreening method to select relevant severe sea states for sloshing loads study. 
Table 5 IACS wave scatter diagram

\begin{tabular}{|c|c|c|c|c|c|c|c|c|c|c|c|c|c|c|c|c|c|c|c|c|}
\hline & \multicolumn{19}{|c|}{$\mathrm{T}_{z}$} & \multirow{2}{*}{ sum } \\
\hline \multirow{18}{*}{$\mathrm{H}_{\mathrm{s}}$} & & 1.5 & 2.5 & 3.5 & 4.5 & 5.5 & 6.5 & 7.5 & 8.5 & 9.5 & 10.5 & 11.5 & 12.5 & 13.5 & 14.5 & 15.5 & 16.5 & 17.5 & 18.5 & \\
\hline & 0.5 & 0 & 0 & 1.3 & 133.7 & 865.6 & 1186 & 634.2 & 186.3 & 36.9 & 5.6 & 0.7 & 0.1 & 0 & 0 & 0 & 0 & 0 & 0 & 3050 \\
\hline & 15 & 0 & 0 & 0 & 293 & 986 & 4976 & 7738 & 5570 & 2376 & 7035 & 1607 & 305 & 51 & 08 & 01 & 0 & 0 & 0 & 22575 \\
\hline & 2.5 & 0 & 0 & 0 & 2.2 & 197.5 & 2159 & 6230 & 7450 & 4860 & 2066 & 644.5 & 160.2 & 33.7 & 6.3 & 1.1 & 0.2 & 0 & 0 & 23810 \\
\hline & 3.5 & 0 & 0 & 0 & 0.2 & 34.9 & 695.5 & 3227 & 5675 & 5099 & 2838 & 1114 & 337.7 & 84.3 & 18.2 & 3.5 & 0.6 & 0.1 & 0 & 19128 \\
\hline & 4.5 & 0 & 0 & 0 & 0 & 6 & 196.1 & 1354 & 3289 & 3858 & 2686 & 1275 & 455.1 & 130.9 & 31.9 & 6.9 & 1.3 & 0.2 & 0 & 13289 \\
\hline & 5.5 & 0 & 0 & 0 & 0 & 1 & 51 & 498.4 & 1603 & 2373 & 2008 & 1126 & 463.6 & 150.9 & 41 & 9.7 & 2.1 & 0.4 & 0.1 & 8328 \\
\hline & 6.5 & 0 & 0 & 0 & 0 & 0.2 & 12.6 & $\begin{array}{l}49.4 \\
167\end{array}$ & 690.3 & 1258 & 1269 & 825.9 & 386.8 & 140.8 & 42.2 & 10.9 & 2.5 & 0.5 & 0.1 & 4806 \\
\hline & 7.5 & 0 & 0 & 0 & 0 & 0 & 3 & 52.1 & 270.1 & 594.4 & 703.2 & 524.9 & 276.7 & 111.7 & 36.7 & 10.2 & 2.5 & 0.6 & 0.1 & 2586 \\
\hline & 8.5 & 0 & 0 & 0 & 0 & 0 & 0.7 & 15.4 & 97.9 & 255.9 & 350.6 & 296.9 & $\begin{array}{l}174.6 \\
\end{array}$ & 77.6 & 27.7 & 8.4 & 2.2 & 0.5 & 0.1 & 1309 \\
\hline & 9.5 & 0 & 0 & 0 & 0 & 0 & 0.2 & 4.3 & 33.2 & 101.9 & 159.9 & 152.2 & 99.2 & 48.3 & 18.7 & 6.1 & 1.7 & 0.4 & 0.1 & 626 \\
\hline & 10.5 & 0 & 0 & 0 & 0 & 0 & 0 & 1.2 & 10.7 & 37.9 & 67.5 & 71.7 & 51.5 & 27.3 & 11.4 & 4 & 1.2 & 0.3 & 0.1 & 285 \\
\hline & 11.5 & 0 & 0 & 0 & 0 & 0 & 0 & 0.3 & 3.3 & 13.3 & 26.6 & 31.4 & 24.7 & 14.2 & 6.4 & 2.4 & 0.7 & 0.2 & 0.1 & 124 \\
\hline & 12.5 & 0 & 0 & 0 & 0 & 0 & 0 & 0.1 & 1 & 4.4 & 9.9 & 12.8 & 11 & 6.8 & 3.3 & 1.3 & 0.4 & 0.1 & 0 & 51 \\
\hline & 13.5 & 0 & 0 & 0 & 0 & 0 & 0 & 0 & 0.3 & 1.4 & 3.5 & 5 & 4.6 & 3.1 & 1.6 & 0.7 & 0.2 & 0.1 & 0 & 21 \\
\hline & 14.5 & 0 & 0 & 0 & 0 & 0 & 0 & 0 & 0.1 & 0.4 & 1.2 & 1.8 & 1.8 & $\begin{array}{ll}.1 .3 \\
\end{array}$ & 0.7 & 0.3 & 0.1 & 0 & 0 & 8 \\
\hline & 15.5 & 0 & 0 & 0 & 0 & 0 & 0 & 0 & 0 & 0.1 & 0.4 & 0.6 & 0.7 & 0.5 & 0.3 & 0.1 & $\begin{array}{l}0.1 \\
0.1\end{array}$ & 0 & 0 & $\frac{0}{3}$ \\
\hline & 16.5 & 0 & 0 & 0 & 0 & 0 & 0 & 0 & 0 & 0 & 0.1 & 0.2 & 0.2 & 0.2 & 0.1 & 0.1 & 0 & 0 & 0 & 1 \\
\hline sum & & 0 & 0 & 1 & 165 & 2091 & 9280 & 19922 & 24879 & 20870 & 12898 & 6245 & 2479 & 837 & 247 & 66 & 16 & 3 & 1 & 10000 \\
\hline
\end{tabular}

Table 6 SSI scatter diagram using uncoupled RAO

\begin{tabular}{|c|c|c|c|c|c|c|c|c|c|c|c|c|c|c|c|c|c|c|c|}
\hline & \multicolumn{19}{|c|}{$T_{x}$} \\
\hline & & 1.5 & 2.5 & 3.5 & 4.5 & 5.5 & 6.5 & 7.5 & 8.5 & 9.5 & 10.5 & 11.5 & 12.5 & 13.5 & 14.5 & 15.5 & 16.5 & 17.5 & 18.5 \\
\hline \multirow{17}{*}{$\mathrm{H}_{2}$} & 0.5 & 0 & 0 & 0 & 0.0000 & 0.0000 & 0.0030 & 0.0060 & 0.0090 & 0.0100 & 0.0130 & 0.0180 & 0.0210 & 0 & 0 & 0 & 0 & 0 & 0 \\
\hline & 1.5 & 0 & 0 & 0 & 0.0000 & 0.0010 & 0.0080 & 0.0190 & 0.0270 & 0.0300 & 0.0400 & 0.0530 & 0.0620 & 0.0680 & 0.0720 & 0.0730 & 0 & 0 & 0 \\
\hline & 2.5 & 0 & 0 & 0 & 0.0000 & 0.0020 & 0.0130 & 0.0310 & 0.0450 & 0.0510 & 0.0670 & 0.0890 & 0.1030 & 0.1130 & 0.1200 & 0.1220 & 0.1200 & 0 & 0 \\
\hline & 3.5 & 0 & 0 & 0 & 0.0010 & 0.0030 & 0.0180 & 0.0440 & 0.0630 & 0.0710 & 0.0930 & 0.1240 & 0.1450 & 0.1580 & 0.1680 & 0.1710 & 0.1680 & 0.1620 & 0 \\
\hline & 4.5 & 0 & 0 & 0 & 0 & 0.0040 & 0.0230 & 0.0560 & 0.0810 & 0.0910 & 0.1200 & 0.1590 & 0.1860 & 0.2030 & 0.2160 & 0.2200 & 0.2160 & 0.2080 & 0 \\
\hline & 5.5 & 0 & 0 & 0 & 0 & 0.0050 & 0.0280 & 0.0690 & 0.0990 & 0.1120 & 0.1470 & 0.1950 & 0.2280 & 0.2480 & 0.2650 & 0.2690 & 0.2640 & 0.2550 & 0.2420 \\
\hline & 6.5 & 0 & 0 & 0 & 0 & 0.0050 & 0.0330 & 0.0810 & 0.1170 & 0.1320 & 0.1730 & 0.2300 & 0.2690 & 0.2930 & 0.3130 & 0.3180 & 0.3120 & 0.3010 & 0.2860 \\
\hline & 7.5 & 0 & 0 & 0 & 0 & 0 & 0.0380 & 0.0930 & 0.1350 & 0.1530 & 0.2000 & 0.2660 & 0.3100 & 0.3380 & 0.3610 & 0.3670 & 0.3610 & 0.3470 & 0.3300 \\
\hline & 8.5 & 0 & 0 & 0 & 0 & 0 & 0.0430 & 0.1060 & 0.1520 & 0.1730 & 0.2270 & 0.3010 & 0.3520 & 0.3830 & 0.4090 & 0.4160 & 0.4090 & 0.3930 & 0.3740 \\
\hline & 9.5 & 0 & 0 & 0 & 0 & 0 & 0.0480 & 0.1180 & 0.1700 & 0.1930 & 0.2530 & 0.3370 & 0.3930 & 0.4290 & 0.4570 & 0.4640 & 0.4570 & 0.4400 & 0.4180 \\
\hline & 10.5 & 0 & 0 & 0 & 0 & 0 & 0 & 0.1310 & 0.1880 & 0.2140 & 0.2800 & 0.3720 & 0.4350 & 0.4740 & 0.5050 & 0.5130 & 0.5050 & 0.4860 & 0.4620 \\
\hline & 11.5 & 0 & 0 & 0 & 0 & 0 & 0 & 0.1430 & 0.2060 & 0.2340 & 0.3070 & 0.4070 & 0.4760 & 0.5190 & 0.5530 & 0.5620 & 0.5530 & 0.5320 & 0.5060 \\
\hline & 12.5 & 0 & 0 & 0 & 0 & 0 & 0 & 0.1560 & 0.2240 & 0.2540 & 0.3330 & 0.4430 & 0.5170 & 0.5640 & 0.6010 & 0.6110 & 0.6010 & 0.5790 & 0 \\
\hline & 13.5 & 0 & 0 & 0 & 0 & 0 & 0 & 0 & 0.2420 & 0.2750 & 0.3600 & 0.4780 & 0.5590 & 0.6090 & 0.6490 & 0.6600 & 0.6490 & 0.6250 & 0 \\
\hline & 14.5 & 0 & 0 & 0 & 0 & 0 & 0 & 0 & 0.2600 & 0.2950 & 0.3870 & 0.5140 & 0.6000 & 0.6540 & 0.6970 & 0.7090 & 0.6970 & 0 & 0 \\
\hline & 15.5 & 0 & 0 & 0 & 0 & 0 & 0 & 0 & 0 & 0.3150 & 0.4130 & 0.5490 & 0.6420 & 0.6990 & 0.7460 & 0.7580 & 0.7450 & 0 & 0 \\
\hline & 16.5 & 0 & 0 & 0 & 0 & 0 & 0 & 0 & 0 & 0 & 0.4400 & 0.5850 & 0.6830 & 0.7440 & 0.7940 & 0.8070 & 0 & 0 & 0 \\
\hline
\end{tabular}

Table 7 SSI scatter diagram using coupled RAO

\begin{tabular}{|c|c|c|c|c|c|c|c|c|c|c|c|c|c|c|c|c|c|c|c|}
\hline & \multicolumn{19}{|c|}{$T_{x}$} \\
\hline & & 1.5 & 2.5 & 3.5 & 4.5 & 5.5 & 6.5 & 7.5 & 8.5 & 9.5 & 10.5 & 11.5 & 12.5 & 13.5 & 14.5 & 15.5 & 16.5 & 17.5 & 18.5 \\
\hline \multirow{17}{*}{$\mathrm{H}_{1}$} & 0.5 & 0 & 0 & 0 & 0.0000 & 2.0010 & 0.0040 & 0.0090 & 0.0170 & 0.0250 & 0.0290 & 0.0300 & 0.0300 & 0 & 0 & 0 & 0 & 0 & 0 \\
\hline & 1.5 & 0 & 0 & 0 & 0.0000 & 0.0020 & 0.0110 & 0.0280 & 0.0500 & 0.0730 & 0.0870 & 0.0910 & 0.0900 & 0.0850 & 0.0790 & 0.0730 & 0 & 0 & 0 \\
\hline & 2.5 & 0 & 0 & 0 & 0.0010 & 0.0030 & 0.0190 & 0.0470 & 0.0830 & 0.1230 & 0.1440 & 0.1520 & 0.1490 & 0.1420 & 0.1320 & 0.1210 & 0.1110 & 0 & 0 \\
\hline & 3.5 & 0 & 0 & 0 & 0.0010 & 0.0040 & 0.0270 & 0.0660 & 0.1160 & 0.1720 & 0.2020 & 0.2120 & 0.2090 & 0.1990 & 0.1850 & 0.1700 & 0.1560 & 0.1420 & 0 \\
\hline & 4.5 & 0 & 0 & 0 & 0 & 0.0050 & 0.0350 & 0.0850 & 0.1490 & 0.2210 & 0.2600 & 0.2730 & 0.2690 & 0.2550 & 0.2380 & 0.2190 & 0.2000 & 0.1830 & 0 \\
\hline & 5.5 & 0 & 0 & 0 & 0 & 0.0070 & 0.0420 & 0.1040 & 0.1820 & 0.2700 & 0.3180 & 0.3330 & 0.3290 & 0.3120 & 0.2900 & 0.2670 & 0.2440 & 0.2230 & 0.2040 \\
\hline & 6.5 & 0 & 0 & 0 & 0 & 0.0080 & 0.0500 & 0.1230 & 0.2150 & 0.3190 & 0.3750 & 0.3940 & 0.3880 & 0.3690 & 0.3430 & 0.3160 & 0.2890 & 0.2640 & 0.2410 \\
\hline & 7.5 & 0 & 0 & 0 & 0 & 0 & 0.0580 & 0.1420 & 0.2480 & 0.3680 & 0.4330 & 0.4540 & 0.4480 & 0.4260 & 0.3960 & 0.3640 & 0.3330 & 0.3040 & 0.2780 \\
\hline & 8.5 & 0 & 0 & 0 & 0 & 0 & 0.0650 & 0.1610 & 0.2810 & 0.4170 & 0.4910 & 0.5150 & 0.5080 & 0.4820 & 0.4490 & 0.4130 & 0.3780 & 0.3450 & 0.3150 \\
\hline & 9.5 & 0 & 0 & 0 & 0 & 0 & 0.0730 & 0.1800 & 0.3140 & 0.4660 & 0.5490 & 0.5760 & 0.5680 & 0.5390 & 0.5020 & 0.4610 & 0.4220 & 0.3850 & 0.3520 \\
\hline & 10.5 & 0 & 0 & 0 & 0 & 0 & 0 & 0.1980 & 0.3470 & 0.5150 & 0.6060 & 0.6360 & 0.6270 & 0.5960 & 0.5540 & 0.5100 & 0.4670 & 0.4260 & 0.3890 \\
\hline & 11.5 & 0 & 0 & 0 & 0 & 0 & 0 & 0.2170 & 0.3800 & 0.5640 & 0.6640 & 0.6970 & 0.6870 & 0.6530 & 0.6070 & 0.5580 & 0.5110 & 0.4670 & 0.4260 \\
\hline & 12.5 & 0 & 0 & 0 & 0 & 0 & 0 & 0.2360 & 0.4130 & 0.6130 & 0.7220 & 0.7570 & 0.7470 & 0.7090 & 0.6600 & 0.6070 & 0.5550 & 0.5070 & 0 \\
\hline & 13.5 & 0 & 0 & 0 & 0 & 0 & 0 & 0 & 0.4460 & 0.6620 & 0.7800 & 0.8180 & 0.8070 & 0.7660 & 0.7130 & 0.6560 & 0.6000 & 0.5480 & 0 \\
\hline & 14.5 & 0 & 0 & 0 & 0 & 0 & 0 & 0 & 0.4790 & 0.7110 & 0.8380 & 0.8790 & 0.8670 & 0.8230 & 0.7650 & 0.7040 & 0.6440 & 0 & 0 \\
\hline & 15.5 & 0 & 0 & 0 & 0 & 0 & 0 & 0 & 0 & 0.7600 & 0.8950 & 0.9390 & 0.9260 & 0.8800 & 0.8180 & 0.7530 & 0.6890 & 0 & 0 \\
\hline & 16.5 & 0 & 0 & 0 & 0 & 0 & 0 & 0 & 0 & 0 & 0.9530 & & 0.9860 & 0.9360 & 0.8710 & 0.8010 & 0 & 0 & 0 \\
\hline
\end{tabular}


Open Access This article is licensed under a Creative Commons Attribution 4.0 International License, which permits use, sharing, adaptation, distribution and reproduction in any medium or format, as long as you give appropriate credit to the original author(s) and the source, provide a link to the Creative Commons licence, and indicate if changes were made. The images or other third party material in this article are included in the article's Creative Commons licence, unless indicated otherwise in a credit line to the material. If material is not included in the article's Creative Commons licence and your intended use is not permitted by statutory regulation or exceeds the permitted use, you will need to obtain permission directly from the copyright holder. To view a copy of this licence, visit http://creativecommons.org/licenses/by/4.0/.

\section{References}

American Bureau of Shipping. Guidance notes on strength assessment of membrane-type LNG containment system under sloshing loads. USA: Houston; 2006.

Abramson HN. The dynamics of liquids in moving containers. NASA Rep. 1966. https://doi.org/10.2514/8.212.

Abramson HN, Bass RL, Faltinsen OM, et al. Liquid slosh in LNG carriers. In: Proceedings 10th IEEE International Symposium on Naval Hydrodynamics. 1974. Cambridge, MA. 1974: ACR-204, pp. 371-388.

Bernard M, Fabien R. Experimental and numerical study of the sloshing motion in a rectangular tank with a perforated screen. J Fluids Struct. 2013;43:463-80. https://doi.org/10.1016/j.jfl uidstructs.2013.10.001.

Bogaert H, Léonard S, Brosset L. Sloshing and scaling: Results from the SLoshel Project. In: Proceeding of of 20th International Offshore and Polar Engineering Conference. 2010. Beijing. pp. 88-97.

Dillingham J. Motion studies of a vessel with water on deck. Mar Technol. 1981;18(1):38-50.

Faltinsen OM, Rognebakke OG, Lukovsky IA, et al. Multidimensional modal analysis of nonlinear sloshing in a rectangular tank with finite water depth. J. Fluid Mech. 2000;407:201-34. https://doi. org/10.1017/S0022112099007569.

Faltinsen OM, Rognebakke OF, Timokha AN. Classification of threedimensional nonlinear sloshing in a square-base tank with finite depth. J. Fluids Struc. 2005;20:81-103. https://doi.org/10.1016/j. jfluidstructs.2004.08.001.

Faltinsen OM, Timokha AN. Sloshing. Cambridge: Cambridge University Press; 2009.

Gou Y, Kim Y, Kim SY, et al. Study on sloshing severity prediction: computation vs. experiment. In: Proceedings of the 7th International Workshop on Ship Hydrodynamics. Shanghai. 2011: pp 311-315.

Kim B, Ryu MC, Jung JH, et al. Identification of critical sea states for sloshing model tests. In: Proceedings of the Society of Naval Architects \& Mar. Eng. SNAME, Washington, USA. 2010.
Kim B, Shin YS. Coupled seakeeping with liquid sloshing in ship tanks. In: Proceeding of the of 27th International Conference on Offshore Mechanics and Arctic Engineering Estoril, Portugal. 2008: pp. 1-11.

Kim Y. A numerical study on sloshing flows coupled with ship motionthe anti-rolling tank problem. J Ship Res. 2002;46(1):56-62.

Kim Y. Artificial damping in water wave problems I: constant damping. Int. J. Offsh. Polar Eng. 2003;13(2):88-93.

Kim Y, Kim SY, Kim J, et al. Comparison of sloshing pressures in 2D and 3D tanks. In: Proceeding of the 8th International Workshop on Ship Hydrodynamics, Seoul, 2013: P1A-3. https://doi. org/10.5574/IJOSE.2012.3.4.225.

Kim Y, Nam BW, Kim DW, et al. Study on coupling effects of ship motion and sloshing. Ocean Eng. 2007;34:2176-87. https://doi. org/10.1016/j.oceaneng.2007.03.008.

Kimmoun O, Ratouis A, Brosset L. Sloshing and scaling: experimental study in a wave canal at two different scales. In: Proceeding of 20th International Offshore and Polar Engineering Conference Beijing. 2010: pp 20-26.

Nam BW, Kim Y, Kim DW, et al. Experimental and numerical studies on ship motion responses coupled with sloshing in waves. J Ship Res. 2009;53(2):68-82. https://doi.org/10.1061/(ASCE)08991 561(2009)21:6(294).

Newman J. The evaluation of free-surface green functions. In: Proceedings of the 4th International Conference on Numerical Ship Hydrodynamic. Washington DC. 1985: pp 4-19.

Newman J. Wave effects on vessels with internal tanks. In: Proc. of 20th Workshop on Water Waves and Floating Bodies. Spitsbergen, Norway. 2005.

Rognibakke OF, Faltinsen OM. Coupling of sloshing and ship motions. J Ship Res. 2003;47(3):208-21.

Salvesen N, Tuck EO, Faltinsen OM. Ship motions and sea loads. Transactions. 1970;78:250-79.

Sclavounos PD. User's manual of NIIRID, MIT Report. 1985.

Teng B, Gou Y, Ning DZ. A higher order BEM for wave-current action on structures-direct computation of free-term coefficient and CPV Integrals. China Ocean Eng. 2006;20(3):395-410. https://doi. org/10.1007/s11249-006-9133-5.

Webster WC. Analysis of the control of activated anti-rolling tanks. Trans SNAME. 1967;74:296-331.

Yung TW, Ding Z, He H, et al. LNG sloshing: characteristics and scaling law. Int. J. Offsh. Polar Eng. 2009;19(4):264-70.

Zheng M, Kim Y, Kim SY. PRESLO JIP Final Report (Preliminary Version). SNU Report. 2014.

Zheng M, Kim Y, Kim SY, et al. Study on the prediction of sloshing severity. In: Proc. of 23rd International Offshore and Polar Engineering Conference Alaska 2013; 3: 320-329.

Zheng M, Kim Y, Kim SY. Sloshing severity prediction and its application to LNG cargo design. In: Proceeding of the 8th International Workshop on Ship Hydrodynamics. Seoul. 2013: P1A-3. 